\title{
Le mâle propre et beau
}

\author{
Erhard Taverna
}

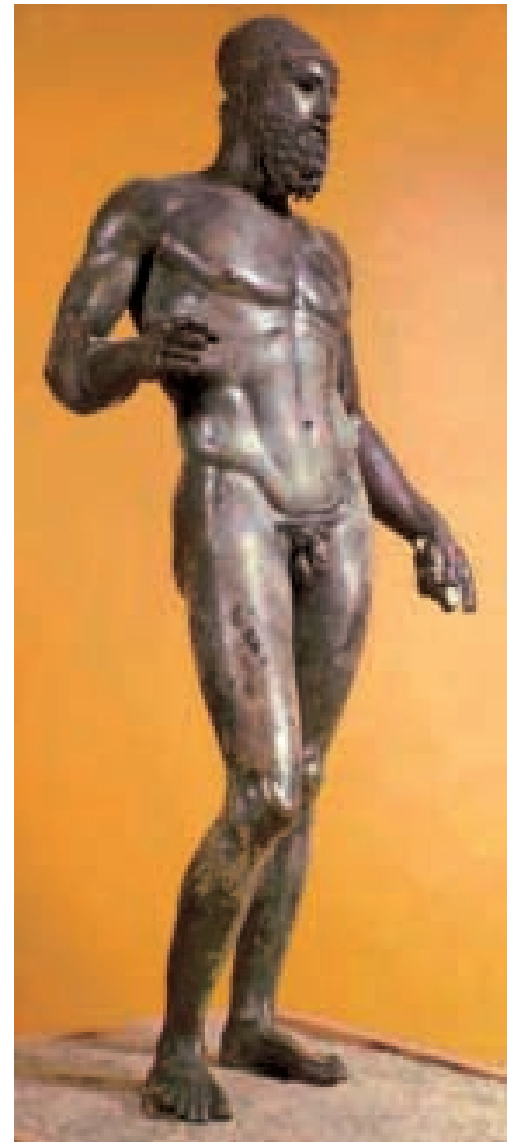

Erinnern Sie sich noch an das empörte Rauschen im helvetischen Pressewald? Die ganze Nation war wieder einmal einig wie selten, als ein böser Lord aus dem fernen Britannien uns mangelnde Hygiene unterstellte. Unappetitliche Waschmuffel seien wir, unterversorgt mit säubernden Einrichtungen und Schlusslichter im internationalen Vergleich des Seifenkonsums. Eine Generation später hat sich vieles geändert, und das Frischgemüse wird nicht mehr in der Badewanne gehortet. Jährlich steigen die Umsatzzahlen kosmetischer Artikel für Frau und Mann, beide sind fit und gesund, sie essen mediterran und lassen sich in der Mittagspause das Fett absaugen, die Haare umfärben oder Botox spritzen. Die häuslichen Regale sind vollgestopft mit Duschgels, Spezialseifen und Shampoos, Bodylotions und Sonnenschutzcrèmes für alle Höhenzonen. Im Reigen der Kleidermoden wandelte sich auch das Körpergefühl.
China schneidert die Klamotten, aber die Grande Nation ist uns wieder einmal punkto «chic» eine Nasenlänge voraus, vor allem der männlichen. Cannes hat am diesjährigen 58. Filmfestival die Wegmarken für die Fans gesetzt. Waren die weiblichen Stars schon immer jung und schön, haben jetzt auch die jungen und alten Männer an ihrer Seite tüchtig aufgeholt. Genügten einst für die väterlichen Sponsoren Massanzüge und eine coole Krawatte, so zeigten sich auch Fossile der Branche wie Dennis Hopper, Woody Allen, Michel Piccoli oder George Lucas erstaunlich verjüngt, geliftet und toupiert, epiliert und mit Bärtchen à la Clark Gable. Die jüngere Crew warb wie die Sportathleten für L'Oréal oder die japanische Konkurrenz Shiseido. Selbst der grosse Jean Baudrillard, Philosoph und Fotograf, hat sich in diesen Tagen im Magazin der «Le Monde» mit nacktem Oberkörper auf der Titelseite präsentiert. Sein intellektuelles Selbstbewusstsein mag ihn darüber hinwegtrösten, dass seine 76jährige Haut noch nicht von den Segnungen zeitgemässer Verjüngungsmittel profitieren konnte. «L'homme se refait une beauté» titelt eine Umfrage unter Männern. Haare sind nicht mehr maskulin und potent, Tarzan posiert seine Muskeln nackt. 180 Tage hat bisher die lebenslängliche Rasur verbraucht, neu im Trend ist die Entfernung aller Körperhaare, sei es mit Klinge und Pinzette oder mit Epilierwachs. Jeder vierte Franzose geht zur Kosmetikerin, appliziert sich eine Gesichtsmaske vor dem Duschen und braucht Bräunungsmittel. Biotherm hydriert die Haut und lindert das Brennen der gelichteten Oberfläche. Noch länger als Erfrischungstücher wirken Sprays gegen das lästige Schwitzen. Lancôme Homme nimmt der Haut den unerwünschten Fettglanz, Clarins bietet die begehrte Mattheit für 24 Stunden, und noch nachhaltiger sind Peeelingmittel, ab 35 Jahren kombiniert mit der Antifaltencrème von Nivea Men. In Paris, Rennes, Metz und Marseille bieten Schönheitszentren dem männlichen Kunden die nötige Einführung zur Produktewahl. Das richtige Wort macht die halbe Werbung. Es heisst nicht "crème antirides» sondern «gel antifatigue», nicht «anticernes» sondern «contour des yeux non fatiguant». Männer suchen nicht Träume wie die Frauen, sie brauchen Gewissheiten. Darum ist die Sprache markig-klar, die Tuben und Flacons 
einfach im Gebrauch, mit geometrischem Design, die Farben nicht Rosa, sondern kühles Grau und Weiss, Marine- oder Stahlblau. Ironie verkauft sich gut, sie erlaubt Distanz zum gefürchteten Weichling. Die Instrumente des Erfolges heissen «Poignées d'amour, Lendemain de fête, Attention les yeux ou sueur froide». Die Kosmetikikonen tragen das Banner des «Mâle tout beau, tout propre». Das Fussballidol Zidane wirbt für Actif Skincare, der Weltmeister im Segeln für
Skinethics, der Fussballstar Beckham für Gucci und die neuen Kuren im kommenden Herbst.

Das Patriarchat tritt endgültig ab, statt Flagge zeigt man Haut. Dafür wird es eng im Badezimmer, denn die neuen Herren sind dort nun öfter anzutreffen. Der Vorteil für die Dame: Sie kann mitreden und darf von den Produkten ihres Partners naschen. Ausserdem sind die neuen männlichen Kreationen bedeutend billiger als die alten weiblichen.

\section{Buchbesprechung}

\section{Der medkalender 2005 ist ein «Must» für alle Ärztinnen und Ärzte}

medkalender 2005. Arzneimittelübersicht. Redaktion: Etzel Gysling, Natalie Marty-Nekora und Susanne Redle. 124. Ausgabe. 816 Seiten, Format 10,5×21 cm. Broschiert. Fr. 78.-. Basel: EMH Schweizerischer Ärzteverlag AG, 2005. ISBN 3-7965-2125-8

Der medkalender 2005 hat zwei Stärken: Format und Inhalt. Er passt in jede Kitteltasche und enthält alle für eine sichere, effiziente und KVG-konforme Pharmakotherapie notwendigen Informationen.

Das Redaktionsteam um Etzel Gysling darf aus dem grossen Fundus des infomed-Verlages zur praxisbezogenen Pharmakotherapie schöpfen. In einem bescheiden mit «Kinetik für die Praxis» betitelten Kapitel werden die wichtigsten Prinzipien der Pharmakotherapie kurz und prägnant abgehandelt. In 20 weiteren Kapiteln werden die Arzneimittel nach Organsystemen und Fachgebieten dargestellt. Der Symptomtherapie wird dabei ein eigenes Kapitel gewidmet. Die Arzneimittelgruppen werden nach einheitlichem System bezüglich Wirkung, Indikation, Nebenwirkungen, Interaktion und besonderen Vorsichtsmassnahmen beziehungsweise Kontraindikationen besprochen. Dieser Einleitung folgt eine tabellarische Aufstellung aller in der Schweiz registrierten pharmazeutischen Spezialitäten. Rasch findet man dort alle notwendigen Angaben: Dosierung, Darreichungsform, Preis, SL-Registrierung (Rückvergütung durch Krankenversicherung). Über entsprechende Register kann auch ausgehend von Markenname, Wirkstoff oder ATC-Code in dieses umfassende Nachschlagewerk eingestiegen werden. Das Preis-Leistungs-Verhältnis stimmt.

Für künftige Auflagen sind an erster Stelle eine Übersetzung ins Französische und an zweiter Stelle die zusätzliche Ausgabe in Form einer CD-ROM als Wünsche anzumelden.

Der medkalender 2005 ist ein «Must» für alle Ärztinnen und Ärzte, in Klinik und Ambulanz. Im Interesse der Patientensicherheit ist dem medkalender 2005 eine möglichst grosse Verbreitung und Anwendung zu wünschen. 